\title{
The Relationship Between Parent Shyness and Child Shyness: Examining the Moderating Effect of Child Gender and Parenting Style*
}

\author{
Han PiGuo \\ Heze University, Heze, China
}

\author{
Wu YunPeng, Gao FengQiang \\ Shandong Normal University, Ji'nan, China
}

\begin{abstract}
A random sample of 535 children was selected by cluster random sampling. The shyness level and parenting style of parents and shyness level of children were investigated. The results indicated that there was a positive correlation between parent shyness and child shyness, and there was a negative correlation between the child shyness and the authoritative parenting style. Mother shyness has a positive effect on different gender child shyness, but father shyness can only positively predict boy's shyness. The authoritarian parenting style has a negative predictive effect on boy's shyness. The authoritative parenting style could significantly enhance the influence of parent shyness on child shyness.
\end{abstract}

Keywords: parent shyness, child shyness, parenting style, child gender, moderating effect

\section{Introduction}

Shyness is the caution and anxiety that individuals felt in face of novel social situations/objects or social evaluation, mainly for the avoidance of conflicts in the context (Rubin, Coplan, \& Bowker, 2009). Shyness of children is usually defined as tension and fear when faced with strangers and unfamiliar situations (Han, Wu, \& Gao, 2014). Shyness is a common psychological phenomenon, some of China's research shows that Chinese people's shyness experience is more widespread (Chen, Gao, \& Wu, 2013). Generally speaking, shyness is considered as a moderate normal reaction, but excessive shyness will adversely affect children's physical and mental health and their normal life. For example, shy children have less peer interaction, showing lower social interaction skills, and tend to produce anxiety in the social scene and withdrawal from social interaction (Coplan, Closson, \& Arbeau, 2007). Shyness made it impossible for children to show true self and have much impact on their personality development (Gao, Gong, \& Qi, 2011). Shyness and mental health of young children are related to some extent (Sun, Fan, \& Wang, 2009). Shy child will encounter more difficulties in the process of school adjustment, which is not conducive to the establishment of good relations between teachers

\footnotetext{
*Acknowledgments: This research was funded by two projects of Humanities and Social Sciences of the Ministry of Education of China (12YJC190004, 12YJC190009), by project of National Social Science Foundation of China (13BSH061), Science and Technology Development Plan Project of Shandong Province (2013GSF11802), Scientific Research Project of Heze University in 2014 (XY14SK02) and Curriculum Reform Project of Heze University in 2014(2014003).

Han PiGuo, M.A., Department of Preschool Education, Heze University. Email: hanpiguo1215@163.com.

Wu YunPeng, Ph.D. candidate, School of Psychology, Shandong Normal University.

Gao FengQiang (Correspondence author), Ph.D., School of Psychology, Shandong Normal University. Email: gaofq11@163.com.
} 
and children and peer relations $(\mathrm{Wu}, \mathrm{Yu}, \mathrm{Chen}, \mathrm{Wu}, \&$ Gao, 2014; Kimberley, Coplan, \& Weeks, 2010). Therefore, taking the universal existence of shyness and its adverse effects on young children into consideration, it's necessary for us to make a deep exploration of its causes and propose practical recommendations to correct shyness.

The shyness of children is affected by many factors, in which family as the most important environmental systems in early childhood development and parents as people with who young children interact most, have particularly significant effect (Bronfenbrenner \& Morris, 2006). First of all, the level of parent shyness affects the level of child shyness to some extent. As early as 1977, Zimbardo has analyzed the relationship between parent shyness and child shyness, and found that there is a high positive correlation between the two. In addition, parenting style is also an important factor to influence the shyness of young children (Chen, Gao, \& $\mathrm{Wu}, 2013)$. Review on the relationship between child shyness and parenting styles indicated that authoritative parenting styles are beneficial for the establishment of the child's sense of security and self-confidence, which is the most effective parenting style to overcome shyness, meanwhile, shyness and other social anxiety behavior are related to two kinds of parenting styles, excessive control and emotional apathy (Chen, Gao, \& Han, 2013). However, these studies only examined the influence of parent shyness or parenting styles on the shyness of children; meanwhile, there is no study exploring the relationship among these three variables. In addition, studies that focused on the early childhood are of great importance for revealing the mechanism of shyness.

\section{Method}

\section{Participants}

This study adopted cluster random sampling method to recruit children in Heze City, Shandong Province. Totally, 600 children's parents as well as 32 kindergarten teachers (all teachers were females) participated in current study. After removing invalid scale, we collected 535 valid scales (valid rate: 89.17\%). Among the children, there were 309 boys and 226 girls (junior class: $n=190$; middle class: $n=171$; senior class, $n=174)$.

\section{Measures}

Parent shyness. The study used the Shyness Scale developed by Cheek in 1983 to explore the shyness level of parents. The scale consisted of 13 items with a 5-point Likert-type scale ranging from 1 to 5 . Scale score was computed as a sum of all items, therefore higher scores indicate higher shyness level. In current study, the Cronbach's alpha of this scale was 0.88 among father and 0.83 among mother participants.

Parenting style. The Parenting Style Questionnaire which was developed by Robinson and revised by Fumei Chen in the Chinese population was applied in current study to measure parenting style. The questionnaire consists of 47 items, including two dimensions, the authoritative (including four factors: warmth, reasoning, democratic participation, easygoing) and authoritarian (including four factors: directiveness, corporal punishment, non-reasoning, verbal hostility). It's a 5-point Likert-type scale. Higher score indicates higher level of respective parenting dimension. In this study, the Cronbach's alphas of the two dimensions were 0.89 and 0.84 respectively, the Cronbach's alphas of these eight factors ranged from 0.58 to 0.74 , which indicated good reliability. In addition, the correlation between dimensions and total score of authoritative 
parenting ranged from 0.84 to 0.86 ; the correlation among factors ranged from 0.58 to 0.66 . The correlation between factor scores in authoritarian parenting styles and total scores ranged from 0.67 to 0.84 ; the correlation among factors ranged from 0.38 to 0.66 .

Child shyness. We used the subscale of shyness of Children's Behavior Questionnaire which was compiled by Rothbart in 2001 to test the level of children's shyness. The subscale includes six items, responses were recorded on a 7-point Likert-type scale ranging from 1 "Definitely does not apply" to 7 "Definitely applies", with higher score indicating higher level of shyness. The Cronbach's alpha was 0.80 in the current sample.

\section{Data Analysis}

The SPSS 17.0 was applied to conduct correlation analysis, $t$-test analysis and multiple regression analysis.

\section{Results}

\section{Demographic Analysis of Early Childhood Shyness}

In order to investigate gender differences in terms of child shyness, we conducted an independent samples $t$-test and found that no significant gender difference was found for the boys and girls, $t(535)=0.824, p=0.410$. In order to investigate the grade difference of child shyness, we conducted $F$-test and found that there were significant grade differences in the kindergarten shyness, $F(535)=4.038, p<0.05$. As the grade increased, levels of shyness decreased. The results of multiple comparative analysis showed that there is no significant difference between junior class children and middle class children in terms of shyness level; but shyness levels of the middle class children and senior class children, junior class children and senior class children were significantly different.

\section{Partial Correlation of Child Shyness, Parent Shyness, and Parenting Style}

Given the significant grade differences in terms of child shyness, so we control the grade, and conduct partial correlation analysis of parent shyness, family parenting styles and child shyness. The findings indicate that child shyness was significantly and positively correlated with parent shyness; child shyness was significantly and negatively correlated with total score of authoritative parenting styles and its four factors as warmth, reasoning, democratic participation, and easygoing. The correlation between child shyness and total score of authoritarian parenting styles was not significant; however, child shyness was significantly and negatively correlated with verbal hostility.

\section{The Moderating Effects of Child Gender and Parenting Style}

The current study applied hierarchical multiple regression to test the moderating effects of child gender and parenting styles (authoritarian and authoritative). The control variable entered in the first step, the predictor variables entered in the second layer, the interaction entered in the third step.

The result of regressions showed that the higher level of parent shyness indicated higher level of child shyness, but authoritative parenting styles and authoritarian parenting styles suggested lower level of child shyness. The child gender mediated the relationship between father's shyness and child shyness as well as the relationship between authoritarian parenting and child shyness. The authoritative parenting played a mediating role on the relationship between parent shyness and child shyness. 
Table 2

Partial Correlation Analysis Among Parent Shyness, Family Parenting Styles, and Child Shyness

\begin{tabular}{|c|c|c|c|c|c|c|c|c|c|c|c|c|c|}
\hline & FS & MS & Ave & Aan & War & Rea & DP & Eas & Dir & $\mathrm{CP}$ & $\mathrm{Nr}$ & VH & Child shyness \\
\hline \multicolumn{14}{|l|}{ FS } \\
\hline MS & $0.479^{* * * *}$ & & & & & & & & & & & & \\
\hline Ave & $-0.364^{* * * *}$ & $-0.258^{* * * *}$ & & & & & & & & & & & \\
\hline Aan & $0.231^{* * *}$ & $0.150^{* *}$ & $-0.550^{* * *}$ & & & & & & & & & & \\
\hline War & $-0.421^{* * *}$ & $-0.332^{* * * *}$ & $0.839^{* * *}$ & $-0.459^{* * * *}$ & & & & & & & & & \\
\hline Rea & $-0.262^{* * * *}$ & $-0.188^{* * * *}$ & $0.840^{* * *}$ & $-0.366^{* * *}$ & $0.613^{* * *}$ & & & & & & & & \\
\hline DP & $-0.249^{* * *}$ & $-0.146^{* *}$ & $0.858^{* * *}$ & $-0.470^{* * *}$ & $0.585^{* * * *}$ & $0.644^{* * *}$ & & & & & & & \\
\hline Eas & $-0.305^{* * * *}$ & $-0.216^{* * * *}$ & $0.857^{* * * *}$ & $-0.571^{* * * *}$ & $0.655^{* * * *}$ & $0.619^{* * * *}$ & $0.646^{* * *}$ & & & & & & \\
\hline Dir & $0.102^{*}$ & 0.087 & $-0.449^{* * * *}$ & $0.850^{* * * *}$ & $-0.318^{* * *}$ & $-0.281^{* * *}$ & $-0.400^{* * *}$ & $-0.521^{* * *}$ & & & & & \\
\hline $\mathrm{CP}$ & $0.229^{* * *}$ & $0.160^{* * *}$ & $-0.491^{* * *}$ & $0.841^{* * * *}$ & $-0.444^{* * *}$ & $-0.323^{* * *}$ & $-0.427^{* * *}$ & $-0.467^{* * *}$ & $0.521^{* * *}$ & & & & \\
\hline $\mathrm{Nr}$ & $0.316^{* * *}$ & $0.169^{* * *}$ & -0.488 & $0.826^{* * *}$ & $-0.476^{* * *}$ & $-0.358^{* * *}$ & $-0.330^{* * *}$ & $-0.501^{* * *}$ & $0.554^{* * *}$ & $0.647^{* * *}$ & & & \\
\hline VP & 0.067 & 0.044 & $-0.284^{* * * *}$ & $0.671^{* * * *}$ & $-0.180^{* * *}$ & $-0.174^{* * *}$ & $-0.317^{* * * *}$ & $-0.282^{* * * *}$ & $0.411^{* * * *}$ & $0.451^{* * * *}$ & $0.370^{* * * *}$ & & \\
\hline Child shyness & $0.278^{* * * *}$ & $0.437^{* * * *}$ & $-0.233^{* * *}$ & -0.021 & $-0.148^{* *}$ & $-0.222^{* * *}$ & $-0.190^{* * * *}$ & $-0.234^{* * * *}$ & -0.008 & 0.029 & -0.002 & $-0.108^{*}$ & \\
\hline
\end{tabular}

Notes. G = gender, MS = mother's shyness, FS = father's shyness, Ave = authoritative, Aan = authoritarian, War = warmth, Rea = reasoning, $\mathrm{DP}=$ democratic participation, Eas = easygoing, $\mathrm{Dir}=$ directiveness, $\mathrm{CP}=$ corporal punishment, $\mathrm{Nr}=$ non-reasoning, $\mathrm{VH}=$ verbal hostility; ${ }^{*} p<0.05,{ }^{* *} p<0.01,{ }^{* * *} p<0.001$ (same in Table 3).

Table 3

Hierarchical Multiple Regression Testing Child Gender and Parenting Style as Moderators on the Relationship Between Parent Shyness and Child Shyness

\begin{tabular}{llll}
\hline \multirow{2}{*}{ Predictors } & Step 1 & Step 2 & \multicolumn{1}{c}{ Step 3} \\
\cline { 2 - 4 } & $\beta$ & $\beta$ & $\beta$ \\
\hline Child grade & $-0.152^{* *}$ & -0.021 & 0.026 \\
Child gender & & -0.001 & 0.011 \\
FS & & 0.103 & $0.499^{* * *}$ \\
MS & & $0.702^{* * *}$ & $0.484^{* * *}$ \\
Ave & $-0.474^{* * *}$ & $-0.509^{* * *}$ \\
Aan & $-0.541^{* * *}$ & $-0.806^{* * *}$ \\
G $\times$ FS & & $-0.675^{* * *}$ \\
G $\times$ MS & & 0.176 \\
G $\times$ Ave & & 0.299 \\
G $\times$ Aan & & & $0.702^{* *}$ \\
FS $\times$ Ave & & & $0.735^{* * *}$ \\
FS $\times$ Aan & & & 0.283 \\
MS $\times$ Ave & & & $0.407^{*}$ \\
MS $\times$ Aan & & & 0.232 \\
R & & 0.253 & 0.333 \\
\hline
\end{tabular}

In order to further explore the moderating effect of gender and authoritative parenting, we conducted simple slope analysis. The result (see Figure 1) indicated that father's shyness can significantly and positively predict boy's shyness (simple slope $=0.499, t(534)=3.714, p<0.001$ ), while the prediction is not significant for girl's level of shyness ( simple slope $=-0.176, t(534)=-1.764, p=0.078$ ). As showed in Figure 2, the 
authoritarian parenting can significantly and positively predict the shyness level of boys (simple slope $=$ $-0.806, t(534)=-5.196, p<0.001$ ), while the prediction is not significant for girl's level of shyness (simple slope $=-0.104, t(534)=-0.691, p=0.490)$. In addition, the authoritative parenting was divided into "low authoritative parenting" group and the "high authoritative parenting" group with regards to one standard deviation below and above the mean score of authoritative parenting. The result of simple slope analysis showed that, for the prediction of the shyness of father (see Figure 3) and mother (see Figure 4), the predicting effects of parent's shyness were positive and significant among "high authoritative parenting" group (father shyness: simple slope $=1.234, t(534)=5.120, p<0.001$; mother shyness: simple slope $=0.890, t(534)=3.854$, $p<0.001$ ), while for those in the "low authoritative parenting" group, the predicting effects were not significant (father shyness: simple slope $=-0.236, t(534)=-1.285, p=0.199$; mother shyness: simple slope $=$ $0.077, t(534)=0.447, p=0.655)$.

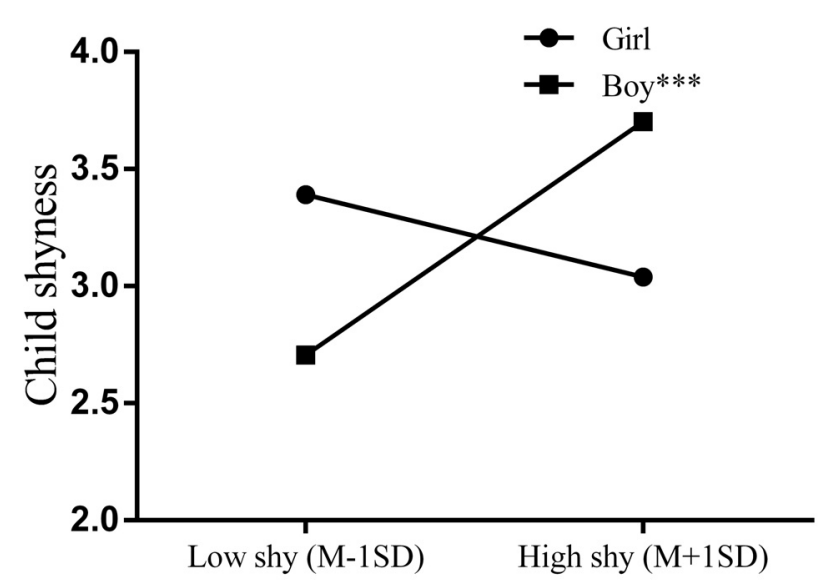

Father shyness

Figure 1. Interaction of child gender $\times$ father shyness.

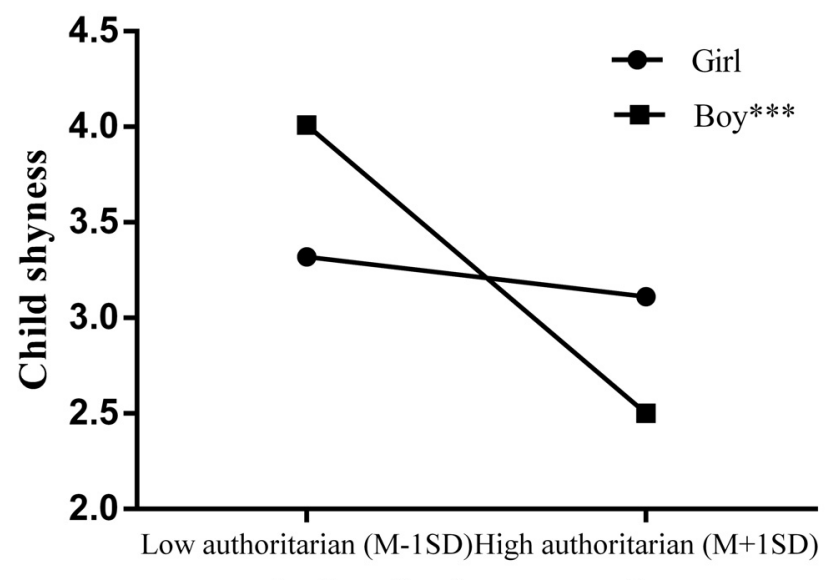

Authoritarian parenting

Figure 2. Interaction of child gender $\times$ authoritarian parenting. 


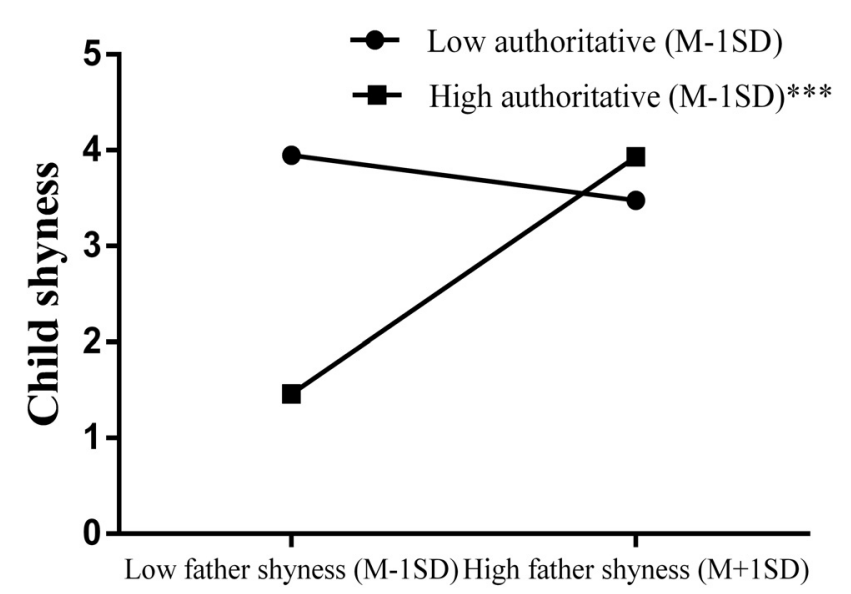

Father shyness

Figure 3. Interaction of authoritative parenting $\times$ father shyness.

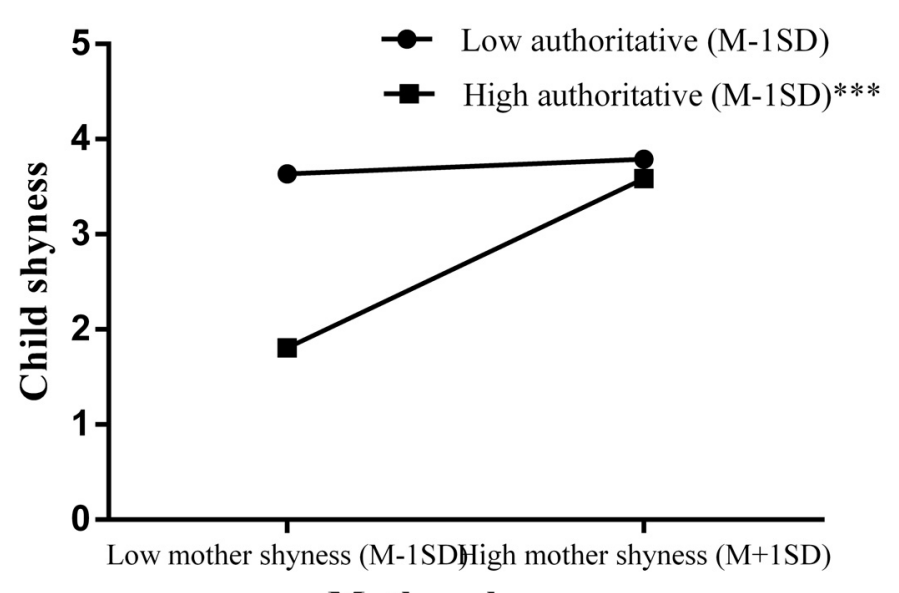

Mother shyness

Figure 4. Interaction of authoritative parenting $\times$ mother shyness.

\section{Discussion}

\section{Differences of Child Shyness on Gender and Grade}

The current study found no gender difference on the shyness level of children, which is not consistent with previous researches. Previous studies with middle school students (Chen et al., 2004) and preschool children ( $\mathrm{Wu}$ et al., in press) indicated that shyness level of girls was higher than that of boys. Meanwhile, current study also indicated that the shyness level of preschool children decreased with the increase of their age.

Overall tendency of shyness varies from stage to stage. Previous studies indicated that individuals' shyness level tended to increase as the increase of grade in the stage from primary school to junior high school and senior high school, and the level becomes stable until college stage (Chen, 2013). The possible reason for this difference is that the shyness level of primary school students and junior high school students derived from the development of self-awareness and self-evaluation capacity, which developed gradually since the late 
childhood (Han, $\mathrm{Wu}, \&$ Gao, in press). However, as the participants in current study were at the stage prior to this period, the main factors that influencing shyness may be the vital change of children's environment (i.e., from home to kindergarten) and their adaption to the change.

\section{Effects of Parent Shyness and Parenting Style on Child Shyness Level}

The result of our study is in accordance with previous research which indicated that parent shyness was correlated with child shyness (Zhang, 2012). As to the causes for such correlation, researchers held different views. Trait theorists believed that shyness was a kind of highly sensitive nervous system, which was obtained by inheritance. Learning theorists believed that shyness was learned because children imitated their parents' behavior of shyness, which was constantly strengthened. However, sociologists argued that shyness was the result of the social environment. The shy behaviors of parents resulted in the lack of children's social situation, and then affected the development of children's social skills, which fostered the formation of child shyness (Chen, 2013). Parents, as the main provider of infant gene, the main object of imitation of children and the main creators of children's environment, played an irreplaceable role in the process of the emergence and development of child shyness.

In addition, results of current study showed that the authoritative parenting style can significantly reduce the level of child shyness, while warm, reasoning, democratic participation, and easygoing family atmosphere can, to some extent, ease child shyness. Those results are consistent with the previous research results (Chen et al., 2013). Many studies have consistently indicated that, among all the family factors that affecting the development of children, parenting style had the greatest and the most direct influence on children, which can make influence the characteristics children in many aspects (Zou, Zhao, \& Su, 2013). Unexpectedly, the current study found that authoritarian parenting was significant and negative correlated with child shyness. Namely, compared with the quiet and lovely "shy" children, parents are more inclined to adopt authoritarian parenting to naughty, noisy "non-shy" children. So there may be the possibility that it is not authoritarian parenting style reduces the level of child shyness, but that parents intend to adopt authoritarian parenting style to "non-shy" children. Future longitudinal research on the relationship between child shyness and parenting style can be conducted to explore this hypothesis.

\section{The Moderating Effect of Child Gender and Parenting Style}

First of all, children's gender had a significant mediation between father's shyness and child shyness, and father's shyness can predict boy's shyness level more strongly and positively. Father is the critical imitating ideal for boys in the family environment. According to Freud's theory, Oedipus complex appeared in the early childhood for boys, but he gave up the desire for his mother because of the castration anxiety, and showed identity with the father, so they tended to imitate his father's behavior. Bandura proposed that boys imitated the behavior of males more than that of females in his social learning theory concerning development of gender role (Liu, 2013).

In addition, children's gender has a significant mediation between authoritarian parenting style and children shyness. In other words, authoritarian parenting was significant and negative correlated with boys' shyness level. However, the pattern was not significant among shy girls. This means that when boys and girls show "non-shy behaviors" (such as naughty and noisy behaviors), parents are more likely to adopt authoritarian parenting practices to boys rather than girls. This result is related with different forms of expression of 
"non-shy behavior" of children with different gender, and it is also consistent with traditional Chinese parenting style.

However, parent shyness does not necessarily lead to child shyness. Besides genetic factors, parenting can also exert important influence on child shyness (Liu, 2013). The results of current study suggested that authoritative parenting style mediated the relationship between parent shyness and child shyness. Parent shyness (both father's and mother's shyness) was significant and positive related with child shyness among parents in "high authoritative parenting" group; while this relationship was not significant among parents in the "low authoritative parenting" group. The reason may be that imitating parents' shyness behavior is an important reason resulting in child shyness (Chen, 2013). It is noteworthy that, under the authoritative parenting circumstance, children are more likely to recognize and imitate parents' behaviors. At the same time, the authoritative parenting is based on mutual understanding and equal exchange between parents and children. The increase of parent-child interaction may make parent behavior shed more influence on the children.

\section{References}

Bronfenbrenner, U., \& Morris, P. A. (2006). The ecology of developmental processes. In W. Damon, \& R. M. Lerner (Eds.), Handbook of child psychology: Theoretical models of human development, 1, 993-1028.

Chen, Y. M. (2013). The structure and characteristics of shyness as well as the effect and mechanism of heredity and the environment on shyness among junior middle school students (Unpublished doctoral dissertation, Shandong Normal University).

Chen, Y. M., Gao, F. Q., \& Wu, Y. P. (2013). Shyness: "Haixiu "or "Xiuqie": Analysis based on concept and etymology. Psychological Science, 36(2), 501-505.

Chen, Y. M., Gao, F. Q., \& Han, L. (2013). Shyness: A review of evidence from behavioral genetics. Advances in Psychological Science, 21(7), 1220-1228.

Chen, Y. M., Wu, Y. P., Zhang, Y. J., Wang, P., Han, L., \& Gao F. Q. (2014). Relationships between parenting style, self-perception and shyness among Chinese early adolescents. Psychology Research, 4(11), 897-904.

Coplan, R. J., Closson, L., \& Arbeau, K. (2007). Gender differences in the behavioral associates of loneliness and social dissatisfaction in kindergarten. Journal of Child Psychology and Psychiatry, 48, 988-995.

Gao, F. Q., Gong, R. Y., \& Qi, D. Y. (2011). The relationship between shyness, loneliness, peer acceptance and self-perceived social competence of pupils. Psychological Research, 27(1), 69-75.

Han, P. G., Wu, Y. P., \& Gao, F. Q. (2014). The development of teacher reported scale for preschool children's shyness. Psychological Research, 7(3), 58-62.

Han, P. G., Wu, Y. P., \& Gao, F. Q. (in press). The shyness and social development of the class children in kindergarten. Chinese Journal of Child Health Care.

Kimberley, A. A., Coplan, R. J., \& Weeks, M. (2010). Shyness, teacher-child relationships, and socioemotional adjustment in grade one. International Journal of Behavioral Development,34(3), 259-269.

Liu, J. H. (2013). The child's development psychology. Shanghai: East China Normal University Press.

Liu, M. N. (2013). A research on the internal relationship between parental rearing style, adolescents self-esteem and subjective well-being. Journal of Nanjing University of Science and Technology, 26(3), 72-79.

Rubin, K. H., Coplan, R. J., \& Bowker, J. C. (2009). Social withdrawal in childhood. Annual Review of Psychology, 60, 141-171.

Sun, Y. Q., Fan,Y. M., \& Wang, P. (2009). Relationship among shyness, post traumatic stress disorder symptom and mental of children who lost their relatives in Wenchuan earthquake. Chinese Journal of Clinical Psychology, 17(4), 164-166.

Wu, Y. P., Yu, Y., Chen, Y. M., Wu, J. F., \& Gao, F. Q. (2014). The exploration and interventions for the maladjustment of shyness preschool children. Chinese Journal of Child Care, 17(4), 484-486.

Wu, Y. P., Wu, J. F., Chen, Y. M., Han, L., Han, P. G., Wang, P., \& Gao, F. Q. (in press). Shyness and school adjustment among Chinese preschool children: Examining the moderating effect of gender and teacher-child relationship. Early Education and Development. 
Xu, C. R. (2011).The study of the relationship between self-respect, internal and external control, parenting control pattern and shyness (Unpublished master's thesis, National Pingdong Normal College).

Zhang, T. (2012). The studies of cognitive bias in the undergraduates of high and low shyness (Unpublished master's thesis, Shandong Normal University).

Zhao, J. X. (2010). Relationships among mother's attachment, parenting style and preschoolers' anxiety. Chinese Journal of Clinical Psychology, 18(6), 806-808.

Zou, R. L., Zhao, D. X., \& Su, Q. X. (2013). Relationship between interpersonal difficulties and parenting pattern of post-90s students. Journal of Shenyang University (Social Science), 15(3), 391-394. 